\title{
APRESENTAÇÃO
}

\section{A cultura digital e a formação dos professores: uma questão em debate}

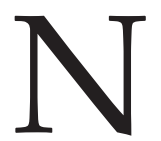

a edição de número 104 da revista Educação \& Sociedade, publicada em outubro de 2008, destacou-se o número temático: "O uso pedagógico das tecnologias de informação e comunicação na formação de professores". $\mathrm{Na}$ ocasião, os organizadores e autores responsáveis pelo número tinham em comum o objetivo de integrar tais tecnologias com a dimensão pedagógica, afastando-a de seu uso instrumentalizado e reificado. Outrossim, tais autores enfatizaram o modo como as chamadas novas tecnologias de informação e comunicação (TIC) se faziam cada vez mais presentes, tanto nas práticas pedagógicas dos professores, quanto em seus respectivos processos de formação.

A presença das TIC no âmbito pedagógico se tornava uma realidade inquestionável não somente nas relações estabelecidas entre professores e alunos nas salas de aula presenciais, como também nas práticas educacionais a distância. A frequência cada vez mais constante de tais tecnologias nas instituições e práticas escolares espelha, na verdade, o modo como a própria tecnologia se espraia para todas as dimensões do mundo da vida.

É interessante observar que as mudanças na esfera da superestrutura sempre ocorreram de forma muito mais lenta do que as modificações relativas à esfera da infraestrutura. Ao refletir sobre as transformações na esfera superestrutural, as quais seriam decorrentes do desenvolvimento das relações de produção capitalistas, Benjamin (2012), fundamentado nas análises críticas de Marx, observou que “O revolvimento da superestrutura, que se processa muito mais lentamente que o da infraestrutura, precisou de mais de meio século para fazer valer, em todos os domínios da cultura, a mudança das condições de produção" (p. 10-11). Ou seja, em tempos da consolidação da Revolução Industrial, as mudanças na esfera da cultura e, portanto, na formação cultural se processaram praticamente após cinquenta anos em relação às modificações nas relações de produção capitalistas, decorrentes do modo como as forças produtivas se desenvolveram. Não por acaso, as escolas de massa no século XVIII se voltavam cada vez mais para a disseminação de modos de conduta propícios ao progresso das relações de produção capitalistas, uma vez que as crianças deveriam aprender tanto os conhecimentos relacionados ao domínio da 
língua vernácula e de matemática e geometria, por exemplo, quanto as formas de comportamento adequadas às relações de produção capitalistas, tais como disciplina, pontualidade e subserviência.

Já no século XXI, o intervalo temporal entre super e infraestrutura, e suas respectivas transformações, se abrevia no mesmo ritmo por meio do qual as denominadas novas tecnologias impingem a reestruturação da própria vida, inclusive no que diz respeito aos processos de ensino e aprendizagem. Atualmente, as modificações na esfera da cultura - decorrentes do modo como a tecnologia se espraia para todas as relações sociais, uma vez que ela, por assim dizer, se torna a "menina dos olhos" do capital - ocorrem numa velocidade impossível de ser mensurada. Em tempos nos quais todas as relações humanas se tornam tecnologizadas, arrefece-se, de forma cada vez mais constante, a possibilidade de se escolher ou não utilizá-las, pois a produção e reprodução da vida se consubstanciam com o ethos tecnológico. Postman, no livro intitulado $O$ desaparecimento da infância, enfatizou as polêmicas oriundas da ocasião da publicação do livro A origem das espécies, de Charles Darwin. Postman observou que, enquanto escrevia seu livro, milhares de pessoas nos Estados Unidos se empenhavam em difamar as ponderações de Darwin em nome da defesa de um tipo de fundamentalismo religioso. Contudo, se isso é possível de ser feito no plano das ideias, cujas consequências não deixam de ter uma dimensão concreta e objetiva, já em relação à presença das tecnologias na vida das pessoas a questão adquire outra dimensão: "Que a luta dessas pessoas seja vã e patética não vem ao caso, porquanto simplesmente se pode viver sem acreditar na evolução. Mas todos temos que enfrentar as condições da comunicação elétrica" (Postman, 1999, p. 83).

O princípio da inevitabilidade da comunicação elétrica - e, atualmente, eletrônica -, enfatizado por Postman, aduz ao fato de que a tecnologia se afirma cada vez mais como modus vivendi, de modo que não pode ser definida apenas como um conjunto de técnicas referentes a determinadas áreas. Justamente por se tornar modus vivendi, ou seja, uma forma de produção e reprodução da vida, compreende-se as razões pelas quais a formação de professores foi associada ao conceito de tecnologias da informação e comunicação (TIC) no dossiê da revista 104, ao passo que hoje esse processo formativo se vincula, na revista 121, ao conceito de cultura digital. Apenas quatro anos separam a publicação de ambas as revistas, mas, efetivamente, torna-se possível conceituar a presença das TIC nos processos comunicacionais, inclusive os desenvolvidos na formação de professores, como uma manifestação de um novo espírito do tempo, de uma nova cultura; uma cultura na qual a palavra digital se faz presente em praticamente todas as relações sociais.

É nessa cultura que o computador não se limita à condição de instrumento de trabalho, mas sim se torna um aparelho que proporciona "a realização de encontros sociais e particulares, processamento e transmissão de dados, a elaboração 
de atividades de trabalho e de diversão, televisão e comunicação, concentração e dispersão, ser ignorado ou ser percebido, a ponto de todas essas potencialidades se tornarem indiscerníveis entre si" (Türcke, 2010, p. 44).

Diante desse contexto, surgem novos desafios concernentes à formação de professores. Isso porque, em tempos nos quais parte significativa do produção e reprodução do conhecimento ocorre por meio do uso de telas e displays, torna-se cada vez mais oportuna e relevante a discussão e reflexão crítica sobre as influências da denominada cultura digital no processo de formação de professores. São tempos em que as palavras convergência e portabilidade alcançam outros planos, haja vista o fato de que o desenvolvimento tecnológico promove a convergência de várias mídias, assim como os aparelhos nos quais essas mídias confluem podem ser transportados e utilizados em quaisquer tempos e espaços. Daí a importância desse dossiê, que reúne artigos de professores(as) cujos objetos de pesquisa versam sobre a forma como tal produção da cultural digital determina modificações profundas nas concepções epístemológicas e práticas pedagógicas dos docentes.

Assim, com o objetivo de suscitar reflexões sobre as transformações decorrentes do processo de digitalização da cultura, as autoras Lílian do Valle e Estrella D’Alva Benayon Bohadana apresentam o artigo "Interação e interatividade: por uma reatropolização da EaD online". Partindo do pressuposto de que o uso intenso das novas tecnologias acarreta profundas modificações em todos os campos da existência humana, as autoras convidam o leitor a refletir sobre o significado do conceito de interatividade, que se faz tão atuante em todas as relações sociais, fato este que implica a necessidade da realização de um tipo de reantropolização da própria concepção de educação a distância.

Raquel Goulart Barreto, autora do artigo "A recontextualização das tecnologias da informação e da comunicação na formação do trabalho docente", tem como principal objetivo investigar o modo como a presença cada vez mais constante das chamadas tecnologias da informação e da comunicação na formação dos professores acarreta modificações estruturais não apenas em relação a novas técnicas de ensino e aprendizagem, como também na própria estruturação da identidade formativa dos docentes. Fundamentada no referencial da análise crítica do discurso e no conceito-chave de recontextualização, Barreto apresenta várias considerações relevantes sobre como a cultura digital determina modificações decisivas no processo formativo dos professores.

No artigo seguinte, cujo título é “Transposição midiática: da sala de aula convencional para a presencial conectada", os autores Gilberto Lacerda e Francisco Garonce apresentam o conceito de transposição midiática como chave de leitura para a compreensão sobre a forma como a presença da tecnologia da videoconferência, 
pela via da internet ou webconferência, nas relações estabelecidas entre professores e alunos, impinge alterações significativas nos papéis que ambos representam quando se encontram na sala de aula. Justamente tais encontros não mais se limitam a esse espaço, uma vez que, por meio da transposição midiática, professores e alunos se encontram digital e sincronicamente a distância.

Já no artigo intitulado "O lema aprender a aprender na literatura de informática educativa", os autores Benedito de Jesus Pinheiro Ferreira e Newton Duarte analisam as concepções pedagógicas que mais se destacam na literatura nacional de informática educativa. Ambos os autores observam a presença marcante tanto das pedagogias do aprender a aprender, pelas vias do construtivismo e do construcionismo, quanto das denominadas pedagogias de competência. Tendo como base epistemológica a pedagogia histórico-crítica, os autores analisam criticamente o modo como os fundamentos teóricos das pedagogias do construtivismo, do construcionismo e da competência se objetivam na literatura da informática educacional, principalmente na forma como tais concepções pedagógicas se materializam nas práticas de ensino e aprendizagem.

Rosa Bueno Fischer, em artigo de instigante título - "Mitologias em torno da novidade tecnológica em educação" -, discute o modo como novas mitologias são engendradas em decorrência da forma como os jovens acessam e se comunicam digitalmente através das chamadas redes sociais. Baseada principalmente nos escritos de Sherry Turckle, Michael Foucault, Marilena Chauí e Muniz Sodré, a autora expõe várias considerações importantes sobre os efeitos da cultura digital nas práticas educacionais e comunicacionais, fato este que determina a construção de novas subjetividades pedagógicas e, por que não dizer, de um novo cenário éticoeducacional.

Na sequência, Maria Elizabeth Bianconcini de Almeida, autora do artigo "Formação de educadores a distância na pós-graduação: potencialidades para o desenvolvimento da investigação e produção do conhecimento", reflete sobre as potencialidades do uso das tecnologias de informação e comunicação nos processos formativos a distância de educadores, em cursos de pós-graduação stricto sensu. Após apresentar ao leitor um panorama concernente ao processo de regulamentação e estruturação da EaD no ensino superior brasileiro, a autora investiga o modo como as TIC contribuem para a reformulação de práticas de interação e produção do conhecimento nos cursos de pós-graduação a distância de nosso país.

Por sua vez, Maria Cristina da Silveira, Danilo Garcia da Silva, Mabel Moreira Strobel e Kátia Morosov Alonso, autores do artigo "Diálogos possíveis: entre a autopoiesis e as tecnologias da inteligência", propõem estabelecer um diálogo entre os pensamentos de Maturana e Varela e Lévy. Em tempos da disseminação cada 
vez maior da cultura digital, os autores argumentam que há correspondências relevantes entre os sistemas autopoéticos, desenvolvidos por Maturana e Varela, e o conceito de tecnologias da inteligência, elaborado por Lévy. A análise de tais correspondências poderá, de acordo com os autores, proporcionar um espaço profícuo para o entendimento do modo como as práticas pedagógicas dos educadores estão sendo modificadas em virtude da presença constante das TIC.

Finalmente, Seraphin Alava, autor do artigo "As práticas em comunáutica no centro da aprendizagem online", parte do pressuposto de que as novas práticas coletivas de comunidades virtuais produzem significativas transformações nas áreas da sociologia, da comunicação, da educação e da economia. No caldo da denominada cultura digital, novas práticas de interação e comunicação desenvolvem-se, sobretudo nas relações estabelecidas entre professores e alunos. Seguindo essa linha de raciocínio, o autor observa a importância de se investigar os efeitos de tais práticas tanto no processo de formação de professores, quanto no modo como os alunos reagem às práticas comunáuticas que se desenvolvem nos sistemas de ensino e aprendizagem online.

Como se pode observar, os textos que compõem esse dossiê primam, sobretudo, pela oferta de reflexões concernentes ao modo como a chamada cultura digital se dissemina de forma cada vez mais acelerada, o que determina necessárias transformações radicais nos processos formativos dos professores e, portanto, na maneira como se relacionam com seus alunos na produção e divulgação do conhecimento. Assim, novos desafios se avizinham quanto à formação dos professores, sobretudo em relação às mudanças curriculares e didáticas e às novas diretrizes para as licenciaturas de formação de professores. A própria relação entre teoria e prática pedagógica inevitavelmente está se transformando, em virtude da mediação constante das TIC no modo como os professores se relacionam com os alunos, seja presencialmente ou a distância. Diante desse contexto, surgem questões concernentes à influência, por um lado, da chamada cultura digital na dimensão pedagógica e, por outro, da dimensão pedagógica na cultura digital. São polêmicas como essa que se fazem presentes nesse dossiê. Portanto, a publicação desse dossiê tem como principal objetivo apresentar ao leitor artigos submetidos espontaneamente pelos pesquisadores anteriormente citados, cujas reflexões certamente auxiliarão a compreender tais desafios, na medida em que a cultura digital se dissemina cada vez mais nas relações pedagógicas.

IVANY Pino

Antônio A. S. Zuin

(Organizadores) 


\section{Referências}

BENJAMIN, W. A obra de arte na época de sua reprodutibilidade técnica. Trad. de Francisco de Ambrosis Pinheiro Machado. Porto Alegre: Zouk, 2012.

POSTMAN, N. O desaparecimento da infância. Trad. de Suzana Menescal de A. Cravalho e José Laurenio de Melo. Rio de Janeiro: Graphia, 1999.

TÜRCKE, C. Sociedade excitada: filosofia da sensação. Trad. de Antônio Zuin, Fabio Durão, Francisco Fontanella e Mario Frungillo. Campinas: Edunicamp, 2010. 